\title{
Fungal communities in gardens of the leafcutter ant Atta cephalotes in forest and cabruca agrosystems of southern Bahia State (Brazil)
}

\author{
Bárbara Monique dos Santos REIS ${ }^{a}$, Aline SILVA ${ }^{a}$, \\ Martín Roberto ALVAREZ ${ }^{a}$, Tássio Brito de OLIVEIRA ${ }^{b}$, \\ Andre RODRIGUES ${ }^{b, c, *}$
}

\author{
${ }^{a} U E S C$ - Santa Cruz State University, Department of Biological Sciences, Ilhéus, BA 45662-900, Brazil \\ ${ }^{b}$ UNESP - São Paulo State University, Department of Biochemistry and Microbiology, Rio Claro, SP 13560-900, Brazil \\ ${ }^{c}$ UNESP - São Paulo State University, Center for the Study of Social Insects, Rio Claro, SP 13560-900, Brazil
}

\section{A R T I C L E I N F O}

Article history:

Received 25 May 2015

Received in revised form

3 September 2015

Accepted 3 September 2015

Available online 11 September 2015

Corresponding Editor:

Nicholas P. Money

\section{Keywords:}

Alien fungi

Atlantic Rainforest

Escovopsis

Fungus garden

Interaction

Symbiosis

\begin{abstract}
A B S T R A C T
Leaf-cutting ants interact with several fungi in addition to the fungal symbiont they cultivate for food. Here, we assessed alien fungal communities in colonies of Atta cephalotes. Fungus garden fragments were sampled from colonies in the Atlantic Rainforest and in a cabruca agrosystem in the state of Bahia (Brazil) in two distinct periods to evaluate whether differences in nest habitat influence the diversity of fungi in the ant colonies. We recovered a total of 403 alien fungi isolates from 628 garden fragments. The prevalent taxa found in these samples were Escovopsis sp. (26\%), Escovopsioides nivea (24\%), and Trichoderma spirale (10.9\%). Fungal diversity was similar between the colonies sampled in both areas suggesting that ants focus on reducing loads of alien fungi in the fungus gardens instead of avoiding specific fungi. However, fungal taxa composition differed between colonies sampled in the two areas and between the sampling periods. These differences are likely explained by the availability of plant substrates available for foraging over habitats and periods. Ordination analysis further supported that sampling period was the main attribute for community structuring but also revealed that additional factors may explain the structuring of fungal communities in colonies of A. cephalotes.
\end{abstract}

(c) 2015 The British Mycological Society. Published by Elsevier Ltd. All rights reserved.

\section{Introduction}

Fungus farming by insects arose independently in ant, termite, and beetle lineages. Such insects usually nourish their fungal partner to obtain nutrients. The majority of ants in the tribe Attini evolved complex fungicultural systems in which mutualistic fungi are cultivated as the main food source for the colony (Weber 1972; Schultz \& Brady 2008;

\footnotetext{
* Corresponding author. Avenida 24-A, n. 1515, Bela Vista, Rio Claro, São Paulo, Brazil, Zipcode: 13.506-900. Tel.: +55 193526 4364; fax: +55 1935264176.

E-mail address: andrer@rc.unesp.br (A. Rodrigues).
}

http://dx.doi.org/10.1016/j.funbio.2015.09.001

1878-6146/@ 2015 The British Mycological Society. Published by Elsevier Ltd. All rights reserved. 
Ward et al. 2015). A subset of species in the tribe Attini, leafcutting ants of the genera Atta and Acromyrmex forage mainly on leaves and flower parts, which serve as substrates for the cultivation of a basidiomycetous fungus, Leucoagaricus gongylophorus. This fungus is the domesticated mutualistic partner grown for food by leafcutter ants (Schultz \& Brady 2008).

Fungus gardens of leaf-cutting ants are continuously threatened by invading fungi carried on and inside the plant substrate foraged by ant workers (Fisher et al. 1996; Rodrigues et al. 2008; Van Bael et al. 2009). In addition, such alien fungi are also transported on the integument of workers and reproductive alates (Guedes et al. 2012; Arcuri et al. 2014). Although several behavioural and chemical strategies employed by ants decrease the microbial loads in the fungus gardens, several fungi endure such strategies and remain in the garden matrix (Fernandéz-Marín et al. 2009). These fungi may ultimately compete with the resident fungal cultivar, as shown in dual culture assays (Silva et al. 2006; Folgarait et al. 2011).

Among such detrimental microorganisms, fungi in the genus Escovopsis are a paramount example of parasites that inhibit the growth of L. gongylophorus (Currie et al. 1999). Considered a mycoparasite of the ant cultivar (Reynolds \& Currie 2004), ant colonies infected with this parasite experience an impact on their fitness, ultimately leading the colony to death (Currie 2001; Wallace et al. 2014). In addition to Escovopsis, several genera of alien fungi are repeatedly found in attine ant colonies and were reported to occur as antagonists of the ant cultivar (Silva et al. 2006; Van Bael et al. 2009).

Although several reports have demonstrated the occurrence and prevalence of alien fungi, few studies have evaluated the factors that influence such fungal communities in fungus-growing attine ant colonies. Previous work indicated that diversity and composition of alien fungi in attine ant colonies varied over a yearlong survey with no apparent patterns (Rodrigues et al. 2011). That study suggested several attributing factors might have accounted for such variations, including the type of substrate foraged by ants and the area where the ants were nesting. However, no other study examined whether such factors are the major attributes that drive alien fungal community structure in attine ant colonies.

To understand the putative factors that explain the structure of fungal communities in leaf-cutting ant colonies, we assessed whether differences in nesting areas influence the fungal communities present in colonies of Atta cephalotes, a species that preferentially occurs in natural areas but also in cabruca agroforest systems in the state of Bahia, Brazil (Delabie 1990). The latter are considered modified agricultural systems because they are used to cultivate cocoa (Theobroma cacao L.) in a semi preserved habitat. Here, we tested variation in the richness, composition, and structure of fungal communities according to the study area. In fact, A. cephalotes is common in primary forests; thus, the plant substrate availability may be a major factor in changes in fungal communities in the fungus gardens. We expected to find that fungal diversity in colonies from cabruca agroforests was lower than in the forests, due to the reduced availability of substrates in the former.

\section{Material and methods}

\section{Sampling}

Fungus gardens of Atta cephalotes were sampled at The Private Reserve of Natural Heritage (RPPN) Serra Bonita, located in the municipalities of Camacan and Pau-Brasil in southern Bahia State, Brazil. This reserve comprises several areas within a distinct altitudinal gradient (between 200 and 990 m). Disturbed areas are abundant in the lower sections of the reserve, including the Cabruca systems and pasture. On the other hand, higher lands or slope lands were not favourable for rearing cattle, so those areas remained intact (hereafter called 'Forest').

Fungus gardens were sampled from six colonies found in the forest and six colonies found in the cabruca. A total of 12 fungus gardens were sampled (Table S1) in two distinct periods: (i) from June 30 to August 4, 2012 (winter) and (ii) from February 18 to March 14, 2013 (summer). Once nests were located, excavation followed the method described in Rodrigues et al. (2014) to avoid having loose soil fall on the top of the fungus garden. Fungus gardens with tending workers and brood (and with alates in some cases) were collected with a sterile spoon, kept in plastic containers and transported to the laboratory for fungal isolation. We observed two sections in all sampled fungus gardens: the top (where new leaf substrate is added) and the bottom part (exhausted substrate). A composite sample made from both sections was plated in the culture media, mostly within 1 or $2 \mathrm{~d}$ after collection, but some samples were plated within 3-4 d after collection (see Table S1 for more details).

\section{Isolation and identification}

Fungus garden fragments of approximately $3 \mathrm{~mm}^{3}$, free of tending workers or brood, were inoculated onto plates containing the following culture media: Potato Dextrose Agar (PDA, Acumedia, a nutrient-rich medium), Malt Agar $2 \%$ (MA2 \%, Acumedia, a nutrient-balanced medium) and Synthetic Nutrient Agar (SNA, a nutrient-poor medium), all supplemented with $150 \mu \mathrm{g} \mathrm{mL}^{-1}$ of chloramphenicol (Sigma-Aldrich, St. Louis, MO, USA). Five garden pieces were inoculated in each of the five plates for each media. Thus, from the 12 gardens sampled, a total of 900 fragments were evaluated in the present study. Plates were incubated at $25{ }^{\circ} \mathrm{C}$, for $14 \mathrm{~d}$ in the dark and monitored daily for fungal growth. Fungi were transferred to MA2 \% plates and checked for any signs of contamination. For sporulating fungi, we carried out monosporic cultures to obtain axenic isolates.

We used a combination of classical and molecular tools to identify the filamentous fungi. First, isolates were screened based on the morphological characteristics of the colony and the microscopic reproductive structures. The resulting morphospecies were further examined and representative isolates were cryopreserved in glycerol $10 \%$ at $-80{ }^{\circ} \mathrm{C}$ and deposited at UNESP-Microbial Resources Center, Rio Claro, SP, Brazil.

Second, we sequenced the internal transcribed spacer (ITS) for representative isolates of each morphoespecies. 
Specifically, for morphospecies that have large number of strains, we sequenced 3-4 strains per morphospecies. For morphospecies that had a single strain, we sequenced the one strain. Genomic DNA extraction followed a combined protocol from Moller et al. (1992) and Gerardo et al. (2004) using fresh mycelia. We amplified the ITS region using the primer pair ITS4/ITS5 (White et al. 1990). For Escovopsis sp., isolates we amplified a fragment comprising the exon 6 of the gene coding for the elongation factor 1-alpha (tef1) with the primer pair EF6-20F/EF6-1000R (Taerum et al. 2007). For PCR, the $25 \mu \mathrm{L}$ reaction volumes consisted of: $1.25 \mathrm{mM}$ of each dNTP, $5.0 \mu \mathrm{L}$ of buffer $5 \times, 2.0 \mu \mathrm{L}$ of $\mathrm{MgCl}_{2}, 1.5 \mu \mathrm{L}$ of each primer and $0.2 \mu \mathrm{L}$ of Taq polymerase. PCR conditions followed Meirelles et al. (2015) and amplicons were cleaned using Wizard ${ }^{\circledR}$ SV Gel and PCR Clean-Up System (Promega). Sequences were bidirectionally sequenced using BigDye ${ }^{\circledR}$ Terminator v.3.1 Cycle Sequencing kit (Life Technologies) in an ABI 3330 sequencer (Life Technologies).

Sequences were assembled in contigs in BioEdit v.7.0.5.3 (Hall 1999) and compared with MegaBlast algorithm with homologous sequences in NCBI-GenBank (www.ncbi.nlm.nih.gov). We also performed searches in the CBS database (www.cbs.knaw.nl). Sequences belonging to the genus Trichoderma were compared with those deposited in the International Subcommission on Trichoderma and Hypocrea Taxonomy (ISTH) database (Druzhinina et al. 2005). Sequences generated in the present study were deposited at the NCBIGenBank under accessions: KR812209-KR812275.

Sequences that showed $97 \%$ or more similarity with reference strain sequences deposited in the databases were considered conspecific (Unterseher \& Schnittler 2010) if the result of morphological analyses also agreed with the identification. For sequences that showed less than $97 \%$ similarity, they were classified to genus or order or were regarded as unidentified fungi.

\section{Analysis of fungal communities}

To explore differences in the abundance of fungi (number of isolates), we compared the proportion of garden fragments with fungi across the two habitats and the three culture media. To test for differences in the proportion of fungi recovered from fungus garden fragments across habitats and culture media, we used the Chi-square test $(P<0.05)$ in R v. 3.0.1 (R Development Core Team 2013). Rarefaction plots were generated to compare species richness (number of species) among habitats and sampling periods. In addition, the Chao 1 estimator was also used to estimate species richness across habitats and sampling periods (Magurran 2004). Fungal diversity (which considers both abundance and species richness) was evaluated by the inverse Simpson (1/D) and Shannon indices. Significant differences among indices were assessed using the Kruskal-Wallis test in R. All diversity indices and rarefaction curves were generated in EstimateS v. 9.1.0 (Colwell 2013).

To determine similarities in composition of fungi between colonies from the two habitats we calculated Jaccard, Sorensen, and Bray-Curtis indices of shared taxa (Magurran 2004). The total number of shared taxa and the exclusive species found in each habitat were represented in a Venn diagram in R. Thus, to analyse the contribution of each species to differences (dissimilarity) of fungal communities, we carried out similarity percentage analysis - SIMPER (Clarke \& Warwick 2001). Finally, to verify the possible factors that shape the fungal communities among the samples from the 12 colonies, we carried out an ordination analysis using nonmetric multidimensional scaling (NMDS) in Past v. $2.17 \mathrm{c}$ (Hammer et al. 2001).

\section{Results}

\section{Abundance of alien fungi in colonies of Atta cephalotes}

From the 900 fungus garden fragments, we recovered filamentous fungi from 628 (69.7\%). The remaining fragments $(n=272)$ showed growth of bacteria, which further prevented the development of the fungal cultivar or any other alien fungi. For this reason, we excluded such fragments from our analyses. Considering only the garden fragments with fungi, a total of 225 fragments (35.8\%, Table S2) showed growth of Leucoagaricus gongylophorus, and 403 fragments (64.1\%, Table 1) were positive for filamentous fungi other than the ant cultivar. The proportion of garden fragments with fungi did not differ between habitats (Fig $1 \mathrm{~A}, \mathrm{H}=0.71$, d.f. $=1$, $P=0.39$ ) or by culture media (Fig $1 B, H=0.63$, d.f. $=2, P=0.72$ ).

Based on morphological markers, we grouped the 403 fungal isolates into 71 morphospecies. Then, representative strains $(n=198)$ within these morphospecies were selected for sequencing. After ITS barcode sequencing (or tef1 sequencing for Escovopsis sp.), the morphospecies represent 34 genera, 66 species, and five unidentified fungi (Tables 1 and S3). Escovopsioides nivea, Escovopsis sp., Trichoderma spirale, and Paecilomyces variotti were the prevalent fungi in colonies sampled in the forest, representing $33 \%, 20 \%, 13.3 \%$, and $8.6 \%$ of the isolates, respectively (Table 1). Similarly, colonies sampled in the cabruca agrosystem showed the same taxa as the prevalent fungi, representing $32 \%, 14 \%, 8.3 \%$, and $7.3 \%$, respectively (Table 1). The remaining fungi accounted for less than $3 \%$ of the abundance and were considered rare species in these communities (Table 1).

Except for P. variotti, the prevalent taxa Escovopsis sp., E. nivea, and T. spirale were consistently present over the two sampling periods. In addition, such taxa occurred in $66 \%$, $66 \%$, and $58.3 \%$, respectively, of the colonies sampled in this study.

\section{Diversity and structure of fungal communities in colonies of Atta cephalotes}

Fungus gardens of A. cephalotes harbour a rich community of alien fungi in addition to the ant cultivar. No significant differences were observed in fungal species richness between the colonies sampled from forest and cabruca or between the sampling periods (Fig S1). Rarefaction curves did not reach an asymptote, indicating that further sampling would reveal additional taxa in this substrate (Fig S1).

Fungus gardens of A. cephalotes in the cabruca agroforest system showed a higher estimated richness of fungal taxa when compared to the forest area (Fig 2A). According to the Shannon and Simpson indices, no significant differences 
Table 1 - Filamentous fungi from fungus garden of Atta cephalotes sampled in the forest and cabruca agrosystems during two sampling periods (winter and summer).

\begin{tabular}{|c|c|c|c|c|c|c|c|c|}
\hline Fungal taxa & $\begin{array}{c}\text { Forest } \\
\text { (winter) }\end{array}$ & $\begin{array}{c}\text { Forest } \\
\text { (summer) }\end{array}$ & $\%^{\mathrm{a}}$ & $\begin{array}{l}\text { Cabruca } \\
\text { (winter) }\end{array}$ & $\begin{array}{l}\text { Cabruca } \\
\text { (summer) }\end{array}$ & $\%^{a}$ & $\begin{array}{l}\text { No. of } \\
\text { isolates }\end{array}$ & $\%^{\mathrm{b}}$ \\
\hline \multicolumn{9}{|l|}{ "Zygomycota" } \\
\hline Cunninghamella sp. & $0^{c}$ & 0 & 0 & 0 & 1 & 0.5 & 1 & 0.25 \\
\hline \multicolumn{9}{|l|}{ Ascomycota } \\
\hline Acremonium sp. & 0 & 0 & 0 & 1 & 0 & 0.5 & 1 & 0.25 \\
\hline Aspergillus flavus & 1 & 0 & 0.5 & 0 & 0 & 0 & 1 & 0.25 \\
\hline Calonectria gracilis & 0 & 0 & 0 & 0 & 1 & 0.5 & 1 & 0.25 \\
\hline Chaetomium sp. & 0 & 0 & 0 & 1 & 0 & 0.5 & 1 & 0.25 \\
\hline Cladosporium tenuissimum & 0 & 0 & 0 & 0 & 1 & 0.5 & 1 & 0.25 \\
\hline Clonostachys rogersoniana & 0 & 1 & 0.5 & 0 & 0 & 0 & 1 & 0.25 \\
\hline Cochliobolus sativus & 0 & 0 & 0 & 1 & 0 & 0.5 & 1 & 0.25 \\
\hline Corynespora sp. & 0 & 0 & 0 & 0 & 1 & 0.5 & 1 & 0.25 \\
\hline Diaporthe helianthi & 1 & 0 & 0.5 & 0 & 0 & 0 & 1 & 0.25 \\
\hline Diaporthe heveae & 1 & 0 & 0.5 & 0 & 0 & 0 & 1 & 0.25 \\
\hline Diaporthe oxe & 0 & 1 & 0.5 & 0 & 0 & 0 & 1 & 0.25 \\
\hline Diaporthe phaseolorum & 1 & 0 & 0.5 & 0 & 1 & 0.5 & 2 & 0.50 \\
\hline Diaporthe schini & 0 & 3 & 1.4 & 1 & 0 & 0.5 & 4 & 0.99 \\
\hline Diaporthe terebinthifolli & 0 & 1 & 0.5 & 0 & 1 & 0.5 & 2 & 0.55 \\
\hline Diaporthe sp. 1 & 0 & 1 & 0.5 & 0 & 0 & 0 & 1 & 0.25 \\
\hline Diaporthe sp. 2 & 0 & 1 & 0.5 & 0 & 1 & 0.5 & 2 & 0.50 \\
\hline Diaporthe sp. 3 & 1 & 0 & 0.5 & 0 & 0 & 0 & 1 & 0.25 \\
\hline Diaporthe sp. 4 & 0 & 1 & 0.5 & 0 & 0 & 0 & 1 & 0.25 \\
\hline Diaporthe sp. 5 & 1 & 0 & 0.5 & 0 & 0 & 0 & 1 & 0.25 \\
\hline Diaporthe sp. 6 & 3 & 0 & 1.4 & 3 & 0 & 1.6 & 6 & 1.49 \\
\hline Escovopsis sp. & 21 & 21 & 20.0 & 34 & 29 & 32.6 & 105 & 26.05 \\
\hline Escovopsioides nivea & 36 & 34 & 33.3 & 27 & 0 & 14.0 & 97 & 24.07 \\
\hline Fusarium equiseti & 0 & 0 & 0 & 1 & 0 & 0.5 & 1 & 0.25 \\
\hline Fusarium oxysporum sp. complex ${ }^{\mathrm{d}}$ & 0 & 0 & 0 & 1 & 2 & 1.6 & 3 & 0.74 \\
\hline Fusarium solani sp. complex & 0 & 0 & 0 & 0 & 2 & 1.0 & 2 & 0.50 \\
\hline Fusarium sp. 1 & 0 & 0 & 0 & 0 & 3 & 1.6 & 3 & 0.74 \\
\hline Fusarium sp. 2 & 0 & 0 & 0 & 0 & 1 & 0.5 & 1 & 0.25 \\
\hline Fusarium sp. 3 & 0 & 1 & 0.5 & 0 & 0 & 0 & 1 & 0.25 \\
\hline Guignardia mangiferae & 0 & 0 & 0 & 0 & 1 & 0.5 & 1 & 0.25 \\
\hline Guignardia sp. & 3 & 0 & 1.4 & 0 & 0 & 0 & 3 & 0.74 \\
\hline Humicola sp. & 3 & 0 & 1.4 & 0 & 0 & 0 & 3 & 0.74 \\
\hline Mariannaea elegans & 0 & 0 & 0 & 1 & 0 & 0.5 & 1 & 0.25 \\
\hline Mycosphaerella sp. & 2 & 1 & 1.4 & 0 & 0 & 0 & 3 & 0.74 \\
\hline Neonectria sp. & 0 & 0 & 0 & 0 & 1 & 0.5 & 1 & 0.25 \\
\hline Paecilomyces variotti & 18 & 0 & 8.6 & 14 & 0 & 7.3 & 32 & 7.94 \\
\hline Paecilomyces sp. 1 & 0 & 0 & 0 & 0 & 1 & 0.5 & 1 & 0.25 \\
\hline Paecilomyces sp. 2 & 0 & 0 & 0 & 0 & 1 & 0.5 & 1 & 0.25 \\
\hline Penicillium sp. 1 & 0 & 1 & 0.5 & 0 & 0 & 0 & 1 & 0.25 \\
\hline Penicillium sp. 2 & 0 & 0 & 0 & 0 & 1 & 0.5 & 1 & 0.25 \\
\hline Penicillium sp. 3 & 0 & 0 & 0 & 1 & 0 & 0.5 & 1 & 0.25 \\
\hline Penicillium sp. 4 & 0 & 1 & 0.5 & 0 & 0 & 0 & 1 & 0.25 \\
\hline Penicillium simplicissimum & 0 & 2 & 1.0 & 0 & 2 & 1.0 & 4 & 0.99 \\
\hline Pestalotiopsis microspora & 0 & 1 & 0.5 & 0 & 1 & 0.5 & 2 & 0.50 \\
\hline Phomopsis asparagi & 0 & 0 & 0 & 0 & 1 & 0.5 & 1 & 0.25 \\
\hline Phomopsis sp. & 4 & 1 & 2.4 & 0 & 4 & 2.1 & 9 & 2.23 \\
\hline Pochonia sp. & 0 & 1 & 0.5 & 1 & 0 & 0.5 & 2 & 0.50 \\
\hline Talaromyces verruculosus & 0 & 0 & 0 & 5 & 1 & 3.1 & 6 & 1.49 \\
\hline Trichoderma citrinoviride & 0 & 0 & 0 & 0 & 1 & 0.5 & 1 & 0.25 \\
\hline Trichoderma hamatum & 0 & 0 & 0 & 0 & 1 & 0.5 & 1 & 0.25 \\
\hline Trichoderma harzianum sp. complex & 0 & 6 & 2.9 & 0 & 0 & 0 & 6 & 1.49 \\
\hline Trichoderma parareeseii & 0 & 0 & 0 & 0 & 1 & 0.5 & 1 & 0.25 \\
\hline Trichoderma spirale & 8 & 20 & 13.3 & 10 & 6 & 8.3 & 44 & 10.92 \\
\hline Trichoderma sp. 1 & 0 & 0 & 0 & 0 & 1 & 0.5 & 1 & 0.25 \\
\hline Trichoderma sp. 2 & 1 & 0 & 0.5 & 1 & 0 & 0.5 & 2 & 0.50 \\
\hline Viridiospora sp. & 0 & 0 & 0 & 1 & 0 & 0,5 & 1 & 0.25 \\
\hline Unidentified Ascomycota 1 & 2 & 0 & 1.0 & 0 & 0 & 0 & 2 & 0.50 \\
\hline Unidentified Ascomycota 2 & 0 & 0 & 0 & 1 & 0 & 0.5 & 1 & 0.25 \\
\hline Unidentified Ascomycota 3 & 0 & 0 & 0 & 3 & 0 & 1.6 & 3 & 0.74 \\
\hline
\end{tabular}


Table 1 - (continued)

\begin{tabular}{|c|c|c|c|c|c|c|c|c|}
\hline Fungal taxa & $\begin{array}{c}\text { Forest } \\
\text { (winter) }\end{array}$ & $\begin{array}{c}\text { Forest } \\
\text { (summer) }\end{array}$ & $\%^{\mathrm{a}}$ & $\begin{array}{l}\text { Cabruca } \\
\text { (winter) }\end{array}$ & $\begin{array}{c}\text { Cabruca } \\
\text { (summer) }\end{array}$ & $\%^{\mathrm{a}}$ & $\begin{array}{l}\text { No. of } \\
\text { isolates }\end{array}$ & $\%^{\mathrm{b}}$ \\
\hline \multicolumn{9}{|l|}{ Basidiomycota } \\
\hline Agaricus sp. 1 & 0 & 0 & 0 & 1 & 0 & 0.5 & 1 & 0.25 \\
\hline Agaricus sp. 2 & 0 & 0 & 0 & 0 & 1 & 0.5 & 1 & 0.25 \\
\hline Coriolopsis rigida & 0 & 1 & 0.5 & 0 & 0 & 0 & 1 & 0.25 \\
\hline Longula sp. & 0 & 0 & 0 & 0 & 1 & 0.5 & 1 & 0.25 \\
\hline Marasmius cladophyllus & 1 & 0 & 0.5 & 0 & 0 & 0 & 1 & 0.25 \\
\hline Phanerochaete sordida & 0 & 0 & 0 & 1 & 1 & 1.0 & 2 & 0.50 \\
\hline Phanerochaete sp. & 0 & 0 & 0 & 0 & 4 & 2.1 & 4 & 0.99 \\
\hline Phlebia sp. & 0 & 1 & 0.5 & 1 & 3 & 2.1 & 5 & 1.24 \\
\hline Phlebiopsis sp. & 0 & 0 & 0 & 0 & 1 & 0.5 & 1 & 0.25 \\
\hline Schizophyllum sp. & 0 & 0 & 0 & 1 & 1 & 1.0 & 2 & 0.50 \\
\hline Unidentified Basidiomycota 1 & 0 & 0 & 0 & 1 & 0 & 0.5 & 1 & 0.25 \\
\hline Unidentified Basidiomycota 2 & 0 & 1 & 0.5 & 0 & 0 & 0 & 1 & 0.25 \\
\hline Total & 108 & 102 & & 113 & 80 & & 403 & \\
\hline
\end{tabular}

a Abundance of fungal isolates (in \%) in the forest and cabruca areas, respectively.

$\mathrm{b}$ Abundance of fungi considering both areas.

c Fungal isolates obtained from the fungus gardens in each area.

d Species complexes are groups of species that share similar morphology but are phylogenetically unrelated (cryptic species).

were observed in fungal diversity between the sampling periods (Kruskal-Wallis, $P>0.05$, Fig $2 B$ ).

Overall, the composition of the fungal taxa markedly differed between gardens from the forest and cabruca because few shared fungal species were observed (mean and standard deviation: Jaccard: $0.05 \pm 0.02$; Sorensen $=0.08 \pm 0.02$ and Bray-Curtis $=0.06 \pm 0.02)$. However, no differences were observed for the sampling periods. The areas shared 17 fungal taxa, which is a low figure when compared to the number of unique fungal taxa found in each area (Fig 3). Surprisingly, the 17 taxa found in both areas comprise 324 isolates, which is more than the number of isolates of unique taxa obtained from gardens in the forest ( $\mathrm{n}=26$ isolates) and in cabruca ( $n=53$ isolates). Thus, this result shows that a few shared species are, in fact, the most abundant ones (Fig 3).

Ordination analysis showed structuring of fungal communities in A. cephalotes colonies. Fungal communities clustered according to the sampling period (coordinate 1), with two exceptions: colonies FO4 and CA7 (Fig 4). In addition, our analyses indicated that colonies FO5, CA7, and CA10 clustered

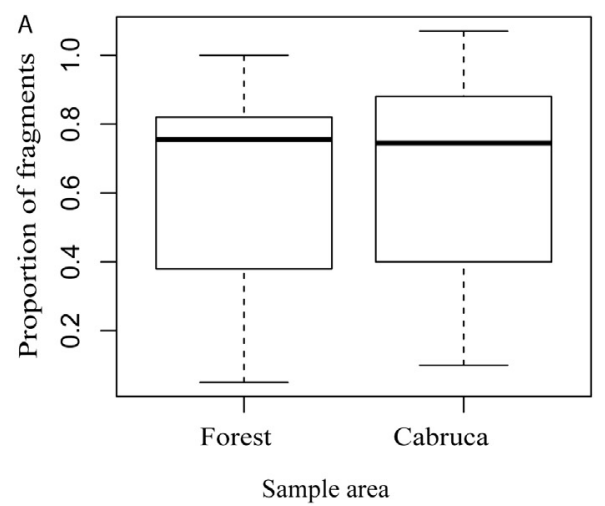

together (Fig 4). These colonies showed the highest abundance of Escovopsis sp., Escovopsioides nivea, and Trichoderma spirale isolates in relation to other fungal species. Additionally, similarity percentage analysis (SIMPER) indicated that Escovopsis sp., E. nivea, and T. spirale are the prevalent alien fungi in gardens of A. cephalotes. Together, these taxa contributed to $50 \%$ of the total dissimilarity of fungal communities in the colonies from the forest and cabruca areas (Table 2).

\section{Discussion}

On the basis of culture-dependent methods, we compared the diversity, composition, and structure of fungal communities in Atta cephalotes colonies in two contrasting habitats. Our results indicated a high abundance of fungi in the garden fragments of A. cephalotes because $64 \%$ of the sampled fragments were positive for these microorganisms. The proportion of fungi was also high in both study areas (Fig 1A). These results support previous findings regarding the

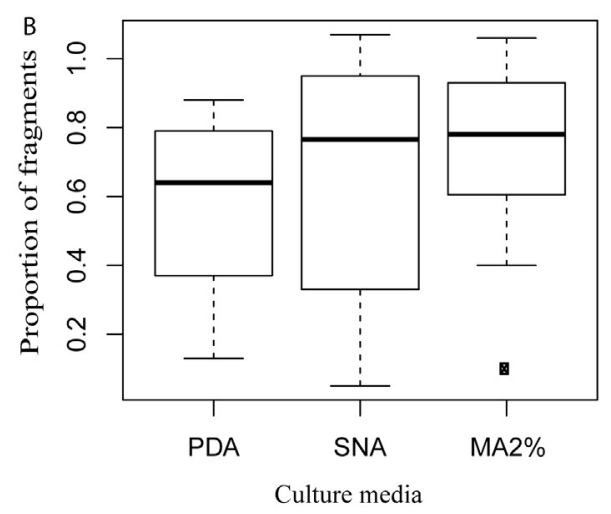

Fig 1 - Proportion of fungus gardens fragments of Atta cephalotes positive for filamentous fungi other than the ant cultivar. (A) Comparison by sampling area (Forest, $n=223$; Cabruca, $n=182$ fragments evaluated) with no significant differences observed; (B) Comparison by culture media. No significant differences were observed in either analysis (P > 0.05). PDA: potato-dextrose agar; SNA: synthetic nutrient agar; MA $2 \%$ : malt agar $2 \%$. 
A) Shannon

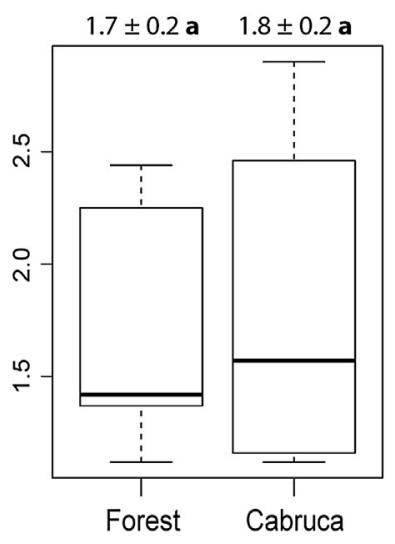

B) Shannon

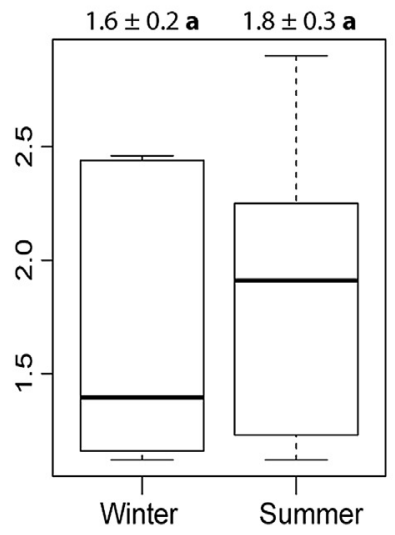

Simpson

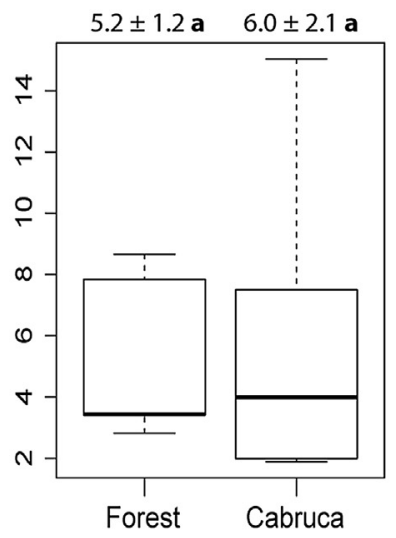

Simpson

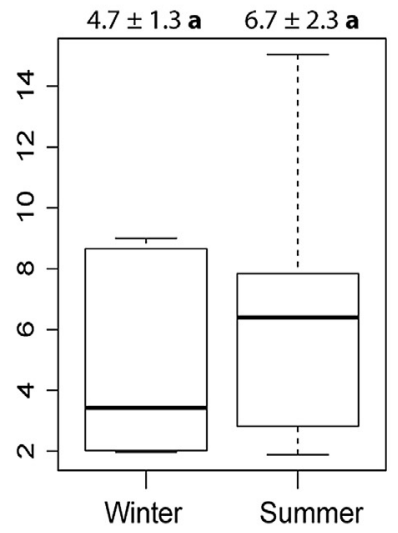

Chao 1

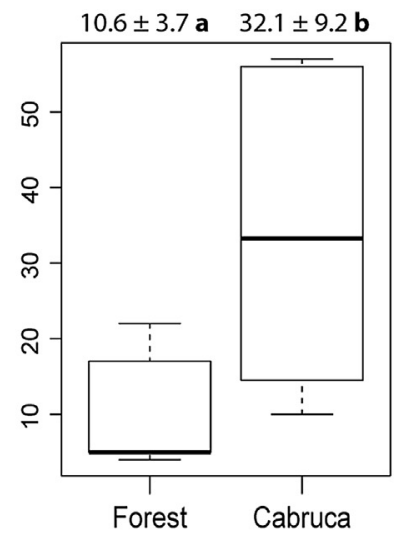

Chao 1

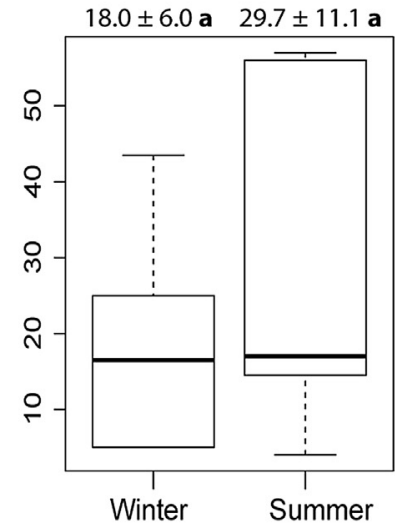

Fig 2 - Diversity and taxa richness of fungal communities found in fungus gardens of the leaf-cutting ant, Atta cephalotes. (A) Comparison between forest and cabruca sampling areas; and (B) sampling periods (winter and summer). Average and standard errors for samples from six gardens for each area and period are indicated above the box plots. Similar letters indicate no significant differences (Kruskal-Wallis, $\mathbf{P}>\mathbf{0 . 0 5}$ ).

prevalence of alien fungi in attine colonies (Fisher et al. 1996; Currie et al. 1999; Rodrigues et al. 2008). These studies used similar methods to evaluate fungal prevalence in attine ant colonies but used one type of culture medium (PDA). Interestingly, when additional culture media were used, similar proportions of fungi were recovered from the fungus gardens (Fig 1B). On the other hand, we observed that each medium differed in taxa composition recovery, with some taxa being isolated preferentially in one medium (data not shown). Multiple lines of evidence suggest that diverse filamentous fungi are continuously present in leaf-cutting ant gardens, even though the ant workers exhibit several mechanisms to avoid the contact of such fungi with the ant cultivar.

Contrary to our predictions, the fungal diversity in colonies of A. cephalotes was similar in both areas and in both sampling periods. This result might be explained by the constant surveillance of ants because worker ants need to protect their gardens against alien fungi (Currie \& Stuart 2001; Currie 2001; Van Bael et al. 2009). Thus, independent from sampling area or period, using chemical and behavioural defences, ants try to reduce the loads of fungi that are incorporated in the garden matrix (Coblentz \& Van Bael 2013) avoiding putative antagonism with the ant fungal cultivar (Silva et al. 2006; Folgarait et al. 2011). Another factor that may explain similarities in fungal diversity is the high abundance of the genera Escovopsis, Escovopsioides, and Trichoderma. These are fast-growing fungi that might have prevented the growth of other slow-growing fungi when the garden fragments were inoculated on the artificial media.

Despite the similarities in diversity, A. cephalotes colonies showed unique fungal communities between the two areas and between the sampling periods (Figs 3 and 4). These differences suggest that ants (or other vectors such as mites) bring different filamentous fungi from the soil and the foraged plant substrate to their nests. Fisher et al. (1996) demonstrated that the diversity and community composition of fungi in the gardens of A. cephalotes maintained in the laboratory varied according to the plant substrate offered to the colonies. Therefore, it is possible that the differences in composition in the present study are related to the provision of different plant 


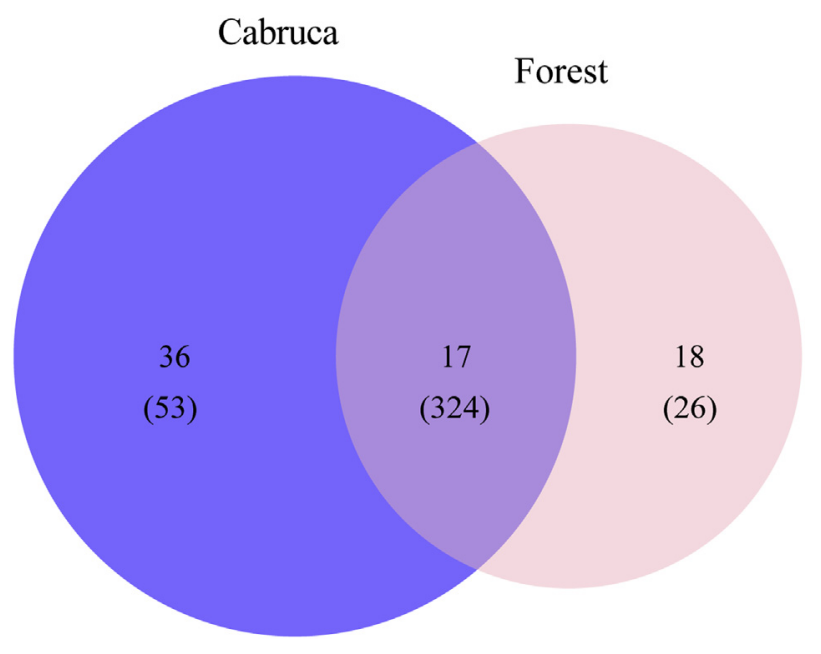

Fig 3 - Venn diagram indicating the number of shared fungal taxa between fungus gardens of Atta cephalotes sampled in the forest and cabruca areas. The size of each circle corresponds to the number of fungal taxa found exclusively in one area. Figures in parentheses indicate the number of isolates recovered from the fungus gardens from each area.

substrates present in the sampling areas, as well as differences in endophytic and epiphytic fungal communities in these substrates. This is supported by the differences in plant species composition between areas (Amorim et al. 2005, 2009; Rocha \& Amorim 2012).

Thus, our results show that $A$. cephalotes colonies differ in the composition of fungal communities but not in the diversity of taxa, corroborating the idea that ants focus on controlling the loads of alien fungi in the garden instead of avoiding specific fungi that are pathogenic to the ant gardens. However, the survival or permanence of these alien fungi in the fungus gardens probably is due to their potential to compete with other microorganisms, their metabolic capability to use the plant material collected by the ants and, their antagonism with the ant cultivar (Silva et al. 2006; Van Bael et al. 2009).

Our analysis of community structure also revealed that the sampling period is a strong factor involved in the structuring of filamentous fungal communities in colonies of A. cephalotes (Fig 4). A variety of factors may explain this result: (i) the differences in the frequency of the foraging behaviour of the ants between the sampling periods (winter and summer); (ii) the variations in the type of plant substrate added in the fungus gardens; or (iii) the presence and abundance of Escovopsis sp., Escovopsioides nivea and Trichoderma spirale, fast-growing fungi that might have influenced the recovery of additional fungi.

Regarding the occurrence of the prevalent fungi, Escovopsis sp. and E. nivea were found in $66.6 \%$ of the colonies evaluated. Escovopsis parasites have been reported from colonies of several genera of attine ants with frequency ranging from $11 \%$ to $75 \%$, especially in Central America (Currie et al. 1999; Currie 2001; Gerardo et al. 2006). On the other hand, Escovopsis is either rare or absent in Atta texana colonies in the United

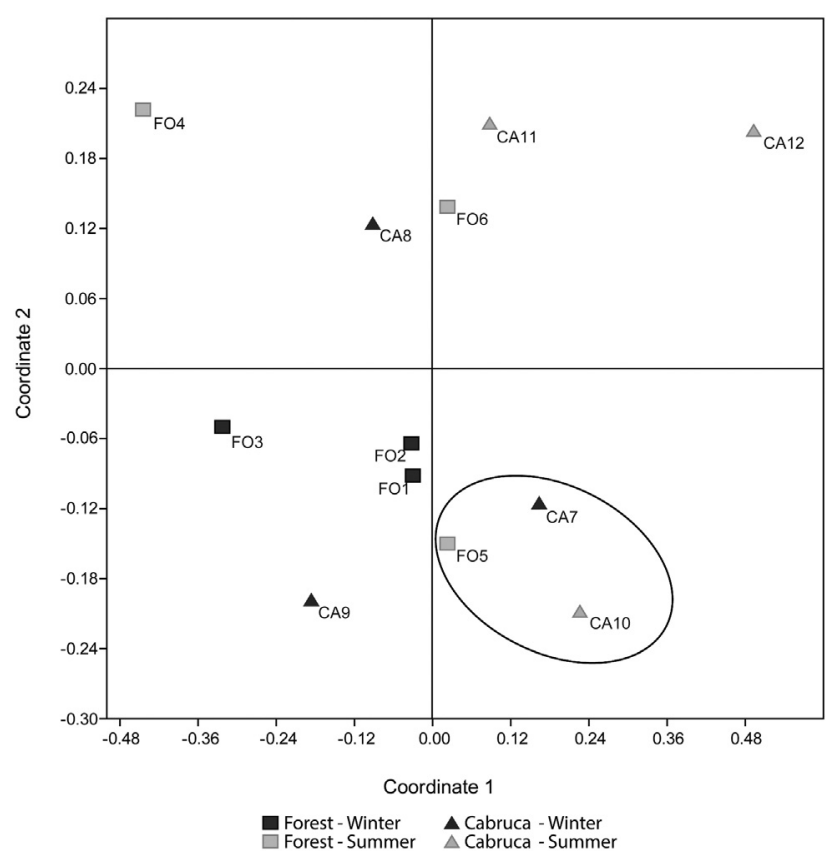

Fig 4 - Nonmetric multidimensional scaling (NMDS) analysis showing structuring of the fungal communities in the gardens of Atta cephalotes. Fungal communities are represented by (i) the nest origin, which includes either the forest (FO1-FO6) or cabruca agrosystems (CA7-CA12) and (ii) the sampling periods, which include winter and summer. Communities separated by sampling period (coordinate 1). Data points circled in black denote colonies with high abundance of Escovopsis sp., E. nivea, and T. spirale isolates. The stress value of this analysis is $\mathbf{0 . 1 2}$.

States (Rodrigues et al. 2011). According to Rodrigues et al. (2005), the parasite was found in $15 \%$ of the Atta sexdens rubropilosa gardens sampled in the state of São Paulo. Conversely, the present study showed that Escovopsis sp. is abundant in A. cephalotes gardens in Brazil, which makes the epidemiological scenario of this parasite quite puzzling, considering that all studies used the same detection method. However, the study by Augustin and colleagues (2013) reported the occurrence of Escovopsioides in $72 \%$ of Acromyrmex spp. colonies

Table 2 - Contribution of the fungal taxa to the overall dissimilarities between fungal communities found in the fungus gardens of Atta cephalotes samples in the forest and the cabruca agroecosystems. Individual contribution (IC), cumulative contribution (CC).

\begin{tabular}{lcc} 
Species & IC (\%) & CC (\%) \\
\hline Escovopsis sp. & 21.93 & 21.93 \\
Escovopsioides nivea & 20.75 & 42.68 \\
Trichoderma spirale & 7.83 & 50.52 \\
\hline
\end{tabular}


found in a particular area in Viçosa, Brazil. The fact that this fungus also occurs in high incidence in a different leafcutting ant (A. cephalotes) may reflect a yet unknown role in fungus-growing attine ant gardens. However, so far, no study has explored the beneficial or pathogenic potential of Escovopsioides, which offers new opportunities for research.

Trichoderma spirale occurred in seven of the 12 sampled nests $(58.3 \%)$. This result is consistent with observations from other studies reporting Trichoderma as a prevalent fungus in the colonies of leaf-cutting ants, such as Atta laevigata (Barbosa 2004) and A. sexdens rubropilosa (Rodrigues et al. $2005,2008)$. In a recent study, where fungi diversity in the soil adjacent to the fungus chambers of A. sexdens rubropilosa and Atta bisphaerica were assessed, Rodrigues et al. (2014) found T. spirale to be the predominant species. Moreover, Trichoderma was found on the integument of winged females Atta capiguara and A. laevigata (Pagnocca et al. 2008). Fungi of the genus Trichoderma are considered possible candidates for the biological control of leaf-cutting ants due to their antagonistic properties with respect to the ant fungal cultivar (Ortiz \& Orduz 2000; Silva et al. 2006; Pagnocca et al. 2012).

The fungal genera Diaporthe, Fusarium, Pestalotiopsis, and Phomopsis each accounted for less than $3 \%$ of the abundance and may be considered endophytes (Van Bael et al. 2009; Bittleston et al. 2011; Rodrigues et al. 2011; Santos et al. 2011; Gomes et al. 2013). Recent studies showed that the ants prefer leaves with low loads of endophytic fungi because the insects take more time cleaning the plant material with the higher abundances of fungi (Bittleston et al. 2011). According to Coblentz \& Van Bael (2013), preference for leaves with a low abundance of endophytic fungi is advantageous due to various factors: (i) showing preference allows the ants to avoid competition between the endophytic fungi and the mutualist fungus (either a direct effect or indirectly by production of secondary compounds) and (ii) the endophytes may have a toxic effect on the ants.

The fact that the filamentous fungi from colonies of $A$. cephalotes are cosmopolitan suggests that they are accidentally transported to nests (Poulsen \& Currie 2006). In this case, many of the fungi isolated in this study may not play a specific role in the ant colony. Compared to the specialized parasitic fungus Escovopsis, these filamentous fungi are considered nonspecific antagonists of the mutualistic fungus (Rodrigues et al. 2008; Pagnocca et al. 2012). Thus, our data provide further evidence that these fungi are transients, but they have the potential to become antagonistic, especially when gardens are stressed (Rodrigues et al. 2005).

In agreement with the results from previous studies on other leaf-cutting ant species, our data show that A. cephalotes colonies are in continuous contact with various filamentous fungi derived from plants and soil. Rodrigues and colleagues (2011) and Pereira et al. (unpublished work) indicated that the plant material added to the fungus garden is one factor that influences fungal communities in leaf-cutting ant colonies. Although fungal richness and diversity did not differ between the two studied areas as we have predicted, we found that fungal community composition varies according to location and sampling period. The forest and the cabruca areas present distinct differences in plant species composition that may offer differential resource opportunities for the ants to forage
(Amorim et al. 2009), which may have contributed to the observed results. Although communities have been differentiated in terms of composition, the observed structure is also explained by the presence of the genus Escovopsis and other fungi found in high abundance; thus, the location and sampling period are not the only factors that influence the diversity and composition of these communities.

\section{Acknowledgements}

We would like to thank the associate editor (Paola Bonfante) and two anonymous reviewers for constructive comments on this manuscript. We are grateful to Dr. Vitor Becker and Mrs. Clemira Souza for logistical help and for providing access to The RPPN Serra Bonita, as well as all the reserve employees, especially, Marcos Cardoso, for aid during fieldwork. This study was supported by CNPq (grant \# 478559/2011-9), FAPESP (grant \# 2011/16765-0) and Santa Cruz University. We also thank CAPES for providing a scholarship to the first author. In addition, we would like to thank ICMBio for the collecting permit (\# 31534) issued to AR.

\section{Appendix A. Supplementary data}

Supplementary data related to this article can be found at http://dx.doi.org/10.1016/j.funbio.2015.09.001.

\section{R E F E R E N C E S}

Amorim AMA, Fiaschi P, Jardim JG, Thomas WW, Clifton BC, Carvalho AMV, 2005. The vascular plants of a forest fragment in southern Bahia, Brazil. Sida 21: 1727-1757.

Amorim AMA, Jardim JG, Lopes MMM, Fiaschi P, Borges RAX, Perdiz RO, Thomas WW, 2009. Angiospermas em remanescentes de floresta montana no sul da Bahia, Brazil. Biota Neotropica 9: 313-348.

Arcuri SL, Pagnocca FC, Melo WG, Nagamoto NS, Komura DL, Rodrigues A, 2014. Yeasts found on an ephemeral reproductive caste of the leaf-cutting ant Atta sexdens rubropilosa. Antonie van Leeuwenhoek 106: 475-487.

Augustin JO, Groenewald JZ, Nascimento RJ, Mizubuti ESG, Barreto RW, Elliot SL, Evans HC, 2013. Yet more "Weeds" in the garden: fungal novelties from nests of leaf-cutting ants. PLoS One 8: e82265.

Barbosa VS, 2004. Efeito da fragmentação florestal na taxa de parasitismo de fungos associados ao jardim da formiga cortadeira Atta laevigata Master dissertation. Universidade Federal de Pernambuco.

Bittleston LS, Brockman F, Wcislo W, Van Bael SA, 2011. Endophytic fungi reduce leaf-cutting ant damage to seedlings. Biology Letters 7: 30-32.

Clarke KR, Warwick RM, 2001. Change in Marine Communities: an approach to statistical analysis and interpretation, 2nd edn. Primer-E, Plymouth.

Coblentz KE, Van Bael SA, 2013. Field colonies of leaf-cutting ants select plants materials containing low abundances of endophytic fungi. Ecosphere 4: art66.

Colwell RK, 2013. EstimateS: statistical estimation of species richness and shared species from samples. Version 9.0. User's Guide and Application. 
Currie CR, 2001. Prevalence and impact of a virulent parasite on a tripartite mutualism. Oecologia 128: 99-106.

Currie CR, Mueller UG, Malloch D, 1999. The agricultural pathology of ant fungus gardens. Proceedings of the National Academy of Sciences USA 96: 7998-8002.

Currie CR, Stuart AE, 2001. Weeding and grooming of pathogens in agriculture by ants. Proceedings of the Royal Society B 268: 1033-1039.

Delabie JHC, 1990. The ant problem of cocoa farms in Brazil. In: Vander Meer RK, Jaffe K, Cedeno A (eds), Applied myrmecology: a world perspective. Boulder, Colorado, pp. 555-569.

Druzhinina I, Kopchinskiy AG, Komon M, Bissett J, Szakacs G, Kubicek CP, 2005. An oligonucleotide barcode for species identification in Trichoderma and Hypocrea. Fungal Genetics and Biology 42: 813-828.

Fernández-Marín H, Zimmerman JK, Nash DR, Boomsma JJ, Wcislo WT, 2009. Reduced biological control and enhanced chemical pest management in the evolution of fungus farming ants. Proceedings of the Royal Society B 276: 2263-2269.

Fisher PJ, Stradling DJ, Sutton BC, Petrini LE, 1996. Microfungi in the fungus gardens of the leaf-cutting ant Atta cephalotes: a preliminary study. Mycological Research 100: 541-546.

Folgarait P, Gorosito N, Poulsen M, Currie CR, 2011. Preliminary in vitro insights into the use of natural fungal pathogens of leaf-cutting ants as biocontrol agents. Current Microbiology 63: 250-258.

Gerardo NM, Currie CR, Price SL, Mueller UG, 2004. Exploiting a mutualism: parasite specialization on cultivars within the fungus-growing ants symbiosis. Proceedings of the Royal Society B 271: 1791-1798.

Gerardo NM, Mueller UG, Currie CR, 2006. Complex host-pathogen coevolution in the Apterostigma fungus-growing ant-microbe symbiosis. BMC Evolutionary Biology 6: 88.

Gomes RR, Glienke C, Videira SIR, Lombard L, Groenewald JZ, Crous PW, 2013. Diaporthe: a genus of endophytic, saprobic and plant pathogenic fungi. Persoonia 3: 1-41.

Guedes FL, Attili-Angelis D, Pagnocca FC, 2012. Selective isolation of dematiaceous fungi from the workers of Atta laevigata (Formicidae: Attini). Folia Microbiologica 57: 21-26.

Hall TA, 1999. BioEdit: a user-friendly biological sequence alignment editor and analysis program for Windows 95/98/NT. Nucleic Acids Symposium Series 41: 95-98.

Hammer $\varnothing$, Harper DAT, Ryan PD, 2001. PAST: paleontological statistics software package for education and data analysis. Palaeontologia Electronica 4: 1-9.

Magurran AE, 2004. Measuring Biological Diversity. Blackwell Science, Oxford.

Meirelles LA, Montoya QV, Solomon SE, Rodrigues A, 2015. New light on the systematics of fungi associated with attine ant gardens and the description of Escovopsis kreiselii sp. nov. PLoS One 10: e0112067.

Moeller EM, Bahnweg G, Sandermann H, Geiger HH, 1992. A simple and efficient protocol for isolation of high molecular weight DNA from filamentous fungi fruit bodies and infected plant tissues. Nucleic Acids Research 20: 6115-6116.

Ortiz A, Orduz S, 2000. In vitro evaluation of Trichoderma and Gliocladium antagonism against the symbiotic fungus of the leaf-cutting ant Atta cephalotes. Mycopathologia 150: 53-60.

Pagnocca FC, Masiulionis VE, Rodrigues A, 2012. Specialized fungal parasites and opportunistic fungi in gardens of attine ants. Psyche 2012: 1-9.

Pagnocca FC, Rodrigues A, Nagamoto NS, Bacci M, 2008. Yeasts and filamentous fungi carried by the gynes of leaf-cutting ants. Antonie van Leeuwenhoek 94: 517-526.
Poulsen M, Currie CR, 2006. Complexity of insect-fungal associations: exploring the influence of microorganisms on attine ant-fungus symbiosis. In: Bourtzis K, Miller TA (eds), Insect Symbiosis. CRC Press, Newbury, pp. 57-77.

Reynolds HT, Currie CR, 2004. Pathogenicity of Escovopsis weberi: the parasite of the attine ant-microbe symbiosis directly consumes the ant-cultivated fungus. Mycologia 96: 955-959.

Rocha DSB, Amorim AMA, 2012. Heterogeneidade altitudinal na Floresta Amazônica setentrional: um estudo de caso no sul da Bahia, Brazil. Acta Botanica Brasilica 26: 309-327.

Rodrigues A, Bacci Jr M, Mueller UG, Ortiz A, Pagnocca FC, 2008. Microfungal "weeds" in the leafcutter ant symbiosis. Microbial Ecology 56: 604-614.

Rodrigues A, Mueller UG, Ishak HD, Bacci Jr M, Pagnocca FC, 2011. Ecology of microfungal communities in gardens of fungusgrowing ants (Hymenoptera: Formicidae): a year-long survey of three species in Central Texas. FEMS Microbiology Ecology 78: 244-255.

Rodrigues A, Pagnocca FC, Bacci Jr M, Hebling MJA, Bueno OC, Pfenning LH, 2005. Variability of non-mutualistic fungi associated with Atta sexdens rubropilosa nests. Folia Microbiologica 50: $421-425$.

Rodrigues A, Passarini MRZ, Ferro M, Nagamoto NS, Forti LC, Bacci M, Sette LD, Pagnocca FC, 2014. Fungal communities in the garden chamber soils of leaf-cutting ants. Journal of Basic Microbiology 54: 1186-1196.

Santos JM, Vrandecic K, Ćosic J, Duvnjak T, Phillips AJL, 2011. Resolving the Diaporthe species occurring on soybean in Croatia. Persoonia 27: 9-19.

Schultz TR, Brady SG, 2008. Major evolutionary transitions in ant agriculture. Proceedings of the National Academy of Sciences USA 105: 5435-54401.

Silva A, Rodrigues A, Bacci Jr M, Pagnocca FC, Bueno OC, 2006. Susceptibility of ant-cultivated fungus Leucoagaricus gongylophorus (Agaricales: Basidiomycota) towards microfungi. Mycopathologia 132: 115-119.

Taerum SJ, Cafaro MJ, Little AEF, Schultz TR, Currie CR, 2007. Low host-pathogen specificity in the leaf-cutting ant-microbe symbiosis. Proceedings of the Royal Society B 274 : 1971-1978.

Unterseher M, Schnittler M, 2010. Species richness analysis and ITS rDNA phylogeny revealed the majority of cultivable foliar endophytes from beech (Fagus sylvatica). Fungal Ecology 10: 366-378.

Van Bael SA, Fernandéz-Marín H, Valencia MC, Roja SEI, Wcislo WT, Herre EA, 2009. Two fungal symbioses collide: endophytic fungi are not welcome in leaf-cutting ant gardens. Proceedings of the Royal Society B 276: 2419-2426.

Wallace DEE, Asensio JGV, Pinto Tomás AA, 2014. Correlation between virulence and genetic structure of Escovopsis strains from leaf-cutting ant colonies in Costa Rica. Microbiology 160: $1727-1736$.

Ward PS, Brady SG, Fisher BL, Schultz TR, 2015. The evolution of myrmicine ants: phylogeny and biogeography of a hyperdiverse ant clade (Hymenoptera: Formicidae). Systematics Entomology 40: 61-81.

Weber NA, 1972. Gardening Ants: the attines. The American Philosophical Society, Philadelphia.

White TJ, Burns T, Lee S, Taylor J, 1990. PCR Protocols: a guide to method and applications. In: Innis MA, Gelfand DH, Sninsky JJ, White TJ (eds), Amplification and direct sequencing of fungal ribosomal rRNA genes for phylogenetics. Academic Press, San Diego, pp. 315-352. 